\title{
Health-related quality of life of children with seizure disorder in Uyo, Nigeria
}

\author{
Mkpouto Udeme Akpan', Frances Sam Okpokowuruk ${ }^{2}$ \\ ${ }^{1}$ Mkpouto Udeme Akpan, ${ }^{2}$ Frances Sam Okpokowuruk, Department of Paediatrics, University of Uyo Teaching Hospital, \\ Uyo, Akwa-Ibom State, Nigeria.
}

Correspondence Author: Dr. Mkpouto Udeme Akpan, Department of Paediatrics, University of Uyo Teaching Hospital, Uyo, Akwa Ibom State, Nigeria. E- mail: mkpoutoakpan@yahoo.com

\begin{abstract}
Background: Seizure disorder is a common chronic neurologic condition in children. Children with seizure disorder have been reported to have a more compromised health-related quality of life compared with healthy children. No known study has been undertaken in our environment. Objectives: To assess the health-related quality of life of children with epilepsy and to compare it with that of apparently healthy children in Uyo, Nigeria. Methods: Child self-report and parent-proxy report questionnaires (Pediatrics Quality of Life inventory version 4.0) were administered to 60 children and their mothers. Thirty of the children had seizure disorders and 30 were apparently healthy children who were age, gender and social class matched with the subjects. Parental education and occupation were used to allot a social class to the children. Results: Of the 30 subjects/controls, 10 (33.3\%) were males while 20 (66.7\%) were females giving a male to female ratio of 1:2. Thirteen belonged to 8-12 years age group, 12 were 13-18 years old while 5 were 5-7 years of age. Majority (27) belonged to the upper and middle social classes and 3 belonged to the lower social class. Twenty children had good seizure control while 10 had one or more seizure episodes per month. Children with seizure disorder had mean total score and mean score in the subscales that was significantly lower than that of the controls. Good quality of life was associated with good seizure control. Conclusion: Children with seizure disorder had lower health related quality of life than apparently healthy children. There is therefore need to maintain good seizure control in children with seizure disorder as it has a positive impact on health-related quality of life of these children.
\end{abstract}

Keywords: Seizure disorder, Health-related quality of life, Uyo, children.

\section{Introduction}

Seizure disorder is a chronic neurologic condition prevalent in children. It has been reported to negatively impact one's physical, social and emotional functions [1]. Worldwide, the prevalence of behavioural disorder in children with seizure disorder ranges from $20 \%$ to $60 \%$ [2-11]. Freilinger et al in Austria reported a prevalence of $22 \%$ [2] while Datta et al reported a prevalence rate of $53.8 \%$ among children with seizure disorder in India [3]. Lagunju et al reported that $46.6 \%$ of children with seizure disorder in Nigeria have behavioural and emotional problems [4].

Feelings of embarrassment, suicidal tendency, low self esteem, and stigmatization are often associated problems among children with seizure disorder [12]. Parents and siblings of children with seizure disorder

Manuscript received: $10^{\text {th }}$ May 2018

Reviewed: $20^{\text {th }}$ May 2018

Author Corrected: $26^{\text {th }}$ May 2018

Accepted for Publication: $30^{\text {th }}$ May 2018 are equally affected by stigmatization. Studies have shown that they are more prone to psychiatric and emotional problems than parents and siblings of children without seizure disorder $[13,14]$.

Health has been defined by World Health Organization (WHO) as a state of complete physical, mental and social well-being and not merely the absence of disease or infirmity [1]. Quality of life (QOL) is an essential aspect of mental and social wellbeing which is often ignored. It is defined as the individual's perception of their position in life in the context of culture and value systems to which they belong and in relation to their goals, expectations, standards and concerns [15].

Stigmatization is a major problem among children with seizure disorder and is associated with poor psychosocial health outcome and impaired Quality of Life (QOL) [12], [16]. 
Editorial

There is paucity of information on the quality of life of children with seizure disorder in Nigeria. Lagunju et al [16] in their study in Ibadan reported poor quality of life in children with seizure disorder but there is no study that compares the quality of life of children with seizure disorder with that of apparently healthy children. This study seeks to compare the quality of life of children with seizure disorder with that of apparently healthy children in Uyo, Nigeria.

\section{Materials and Method}

Study location/area: The study was conducted in the Paediatric Neurology clinic as well as Children's OutPatient (CHOP) of the University of Uyo Teaching Hospital (UUTH), Uyo. UUTH is the only tertiary health facility in Uyo, the capital of Akwa-Ibom State.

The hospital serves as a referral centre for patients from within and outside the state. The Paediatric Neurology clinic is a specialty clinic which is run on Tuesdays along with the general Paediatric clinic. The clinic sees an average of 17-20 patients with neurological conditions per day of consultation. The clinic has a complement of staff from Resident doctors, doctors on internship, trained nurses with the Paediatric Neurologist as the leader of the team.

Study design and study period: This prospective study was conducted over a three-month period from $1^{\text {st }}$ January, 2018 to $31^{\text {st }}$ March, 2018.

Consent: Ethical clearance was obtained from the ethical committee of the University of Uyo Teaching Hospital, Uyo before embarking on the study. Written consent and assent were obtained from both the mothers and the older children before recruiting them into the study.

\section{Inclusion criteria}

Subjects: - 1. Children between the ages of 5years and 18 years with seizure disorder lasting not less than one month since diagnosis. 2. Children whose parents have given consent, or the children have assented to their recruitment into the study.

Controls: - 1. Children aged 5years to 18 years who do not have seizure disorders or any other chronic health condition such as cerebral palsy, nephrotic syndrome, asthma or sickle cell anaemia but presented in hospital for follow up for an acute health condition such as malaria and upper respiratory tract infection that had been treated. 2. Children whose parents/ caregivers have given their consent/assent

\section{Exclusion criteria}

1. Children whose parents did not give consent /assent

2. Children with other chronic conditions in association with seizure disorders.

Instrument and method: The subjects were consecutively recruited as well as the controls and were matched by age, sex and social class with the subjects.

Information such as the age, gender, type of seizure, medications used in treating the seizures, age of the child at onset of seizure were obtained from the children's case-notes. Parental educational attainment and occupation were used to allot a social class to the children using the scheme proposed by Oyedeji [17].

Quality of life was assessed using pediatrics' quality of life inventory version 4.0 parent-reported scale as well as child reported scale $[18,19]$. The instrument categorizes the children into three groups: the young child aged 5-7years, the children aged 8-12 years, and the teens aged 13-18years. It is a modular approach to measuring health related quality of life (HRQOL) in children and adolescents. It consists of brief, practical, generic score scales which test four domains of physical, emotional, social and school functioning. It contains 23 items suitable for use in healthy school and community populations. It is also used in paediatric populations with acute and chronic health conditions. Standard questionnaires, adapted from the pediatric QOL Questionnaire, were administered to the children and their mothers.

Parents' as well as the children's scales were used to assess the children's QOL. This was done by asking the mother and the child about any problems the child had in the last month from the four domains: physical (eight items), emotional (five items), social (five items) and school (five items) functioning domains. The child's physical functioning was measured in terms of problems in walking more than a block, running, participating in sports activities, lifting heavy objects, taking a bath or shower by themselves, doing chores around the house, having aches, and low energy levels.

The child's emotional functioning was measured in terms of feeling afraid or scared, sad, angry, have trouble sleeping, and worry about what will happen to them. The child's social functioning was measured in terms of problems in getting along with other children, getting teased by other children, keeping up when playing with other children, worrying about not being able to do things other children their age can do, and 


\section{Editorial}

other children not wanting to befriend them. The child's school functioning was assessed in terms of problems in paying attention in class, forgetting things, keeping up with the school work, missing school because of not being well, and missing school to go to the doctor or hospital. The scoring system was based on the terms of children's QOL. Each question was scored as grades 0, $1,2,3$ and 4 .

The question was scored 0 when the child or mother answered no problem, scored 1 when the response was almost never a problem, scored 2 when the response was sometimes a problem, 3 if the response was often a problem and scored 4 if the response was almost always a problem. Items were transformed to a 0-100 scale as follows: $0=100,1=75,2=50,4=25$ and $4=0$ with the higher scores indicating a better HRQOL. The mean total score scale was computed as the sum of all the items over the number of items answered on all the scales. The average score for each domain was obtained by summing up all the scores and dividing the sum by the total number of questions answered. High scores signified good quality of life while a score below a certain cut off was taken as poor quality of life. For child report, the cut off was as follows: total 69.7, physical 72.98, psychosocial 66.03; and for parent report, total score 65.4, physical 63.28 and psychosocial 64.38 [20]. The physical health summary score was the same as the physical functioning scale score. The mean psychosocial health summary score was computed as the sum of the items over the number of items answered in the emotional, social, and school functioning scales.

Data was analyzed using SPSS version 20. The results were presented as tables. Chi square was used for comparison between categorical data while student ttest was used for comparison of means. A p-value of $<0.05$ was considered statistically significant.

\section{Results}

Of the sixty children recruited during the study period, thirty were children with seizure disorder (subjects) while the remaining thirty were apparently healthy children (controls). Of the 30 subjects/controls, $13(43.3 \%)$ were in the $8-12$ years age bracket, $12(40.0 \%)$ were in the 13-18years age bracket and 5(16.7\%) were in the 5-7years age bracket.

Majority $(66.7 \%)$ of the children were females with a male to female ratio of 1:2. Forty percent of the children belonged to social class III, $36.7 \%$ belonged to social class II and no child belonged to social class V. The socio-demographic characteristics of the children are as shown in table 1 .

Table-1: Socio-demographic characteristics of the study population.

\begin{tabular}{|c|c|c|}
\hline \multicolumn{2}{|c|}{ Age(years) } & N (\%) \\
\hline $5-7$ & & $5(16.7)$ \\
\hline $8-12$ & $13(43.3)$ \\
\hline $13-18$ & $12(40.0)$ \\
\hline Gender & \\
\hline Male & $10(33.3)$ \\
\hline Female & $20(66.7)$ \\
\hline Social class & $4(13.3)$ \\
\hline I & $11(36.7)$ \\
\hline II & $12(40.0)$ \\
\hline III & $3(10.0)$ \\
\hline IV & $0(0.0)$ \\
\hline V & \\
\hline
\end{tabular}

Table 2 shows the clinical characteristics of the children with seizure disorder. Twenty-six $(86.7 \%)$ of the children had generalized seizures while $4(13.3 \%)$ had partial seizures. Regarding seizure frequency, majority $(66.7 \%)$ of the children had been seizure free for at least one month before being recruited into the study, $3(10 \%)$ each had seizure once a month, twice a month and more than thrice a month while one $(3.3 \%)$ had seizures thrice a month. Twenty-two $(73.3 \%)$ were on one antiepileptic drug while eight were on two antiepileptic medications. For those on one anti-epileptic drug, twenty-one had carbamazepine while one had ethosuxamide. 
Editorial

Table-2: Clinical characteristics of children with seizure disorder.

\begin{tabular}{|c|c|}
\hline & N (\%) \\
\hline Generalized & $26(86.7)$ \\
\hline Partial & $4(13.3)$ \\
\hline Seizure frequency & $20(66.7)$ \\
\hline No seizure & $3(10.0)$ \\
\hline Once a month & $3(10.0)$ \\
\hline Twice a month & $1(3.3)$ \\
\hline Thrice a month & $3(10.0)$ \\
\hline More than thrice a month Seizure medications \\
\hline Monotherapy & $22(73.3)$ \\
\hline Two medications & $8(26.7)$ \\
\hline
\end{tabular}

Mean scores of children with seizure disorder was significantly lower than the mean scores of apparently normal children on all the domains using both the children reported scales as well as parent-proxy reported scales.

Table-3: Mean self-reported health related quality of life in children with seizure disorder and children without seizure disorder.

\begin{tabular}{|c|c|c|c|c|}
\hline & $\begin{array}{c}\text { Children with seizure } \\
\text { disorder Mean (SD) }\end{array}$ & $\begin{array}{c}\text { Children without seizure disorder } \\
\text { Mean (SD) }\end{array}$ & T & p-value \\
\hline Total & $76.12(18.45)$ & $92.28(8.93)$ & -4.29 & 0.000 \\
\hline Physical & $77.92(24.55)$ & $93.54(11.49)$ & -3.12 & 0.004 \\
\hline Emotional & $82.33(20.16)$ & $91.67(11.55)$ & -2.10 & 0.045 \\
\hline Social & $77.67(23.18)$ & $92.67(12.02)$ & -3.45 & 0.002 \\
\hline School & $65.72(25.34)$ & $90.50(10.93)$ & -5.01 & 0.000 \\
\hline Psycho-social & $75.26(18.49)$ & $91.47(9.19)$ & -4.53 & 0.000 \\
\hline
\end{tabular}

The child reported mean scores for both subjects and controls were as follows: total $76.12+18.45$ versus $92.28+8.93$ $(\mathrm{p}=<0.01)$, physical domain $77.92+24.55$ versus $93.54+11.49(\mathrm{p}=0.004)$, emotional domain $82.33+20.16$ versus $91.67+11.55(\mathrm{p}=0.045)$, social $77.67+23.18$ versus $92.67+12.02(\mathrm{p}=0.002)$, school domain $65.72+25.34$ versus $90.50+10.93(\mathrm{p}=<0.001)$ and psycho-social $75.26+18.49$ versus $91.47+9.19(\mathrm{p}=<0.001)$. This is shown in table 3

Table-4: Mean Parent-proxy reported health related quality of life in children with seizure disorder and children without seizure disorder

\begin{tabular}{|c|c|c|c|c|}
\hline & $\begin{array}{c}\text { Parent(Subjects) } \\
\text { Mean (SD) }\end{array}$ & $\begin{array}{c}\text { Parent (Control) } \\
\text { Mean(SD) }\end{array}$ & T & p-value \\
\hline Total & $74.36(26.47)$ & $91.05(8.96)$ & -3.96 & 0.000 \\
\hline Physical & $78.19(26.47)$ & $90.83(12.36)$ & -2.29 & 0.029 \\
\hline Emotional & $77.83(19.90)$ & $89.00(10.54)$ & -2.59 & 0.015 \\
\hline Social & $79.67(25.05)$ & $94.83(9.87)$ & -3.02 & 0.005 \\
\hline School & $63.33(25.47)$ & $88.73(16.11)$ & -5.31 & 0.000 \\
\hline Psycho-social & $72.96(20.81)$ & $91.17(9.54)$ & -4.21 & 0.000 \\
\hline
\end{tabular}

The parent-proxy reported mean scores for both subjects and controls were as follows: Total mean score $74.36+21.20$ versus $91.05+8.96(\mathrm{p}=<0.001)$, physical domain $78.19+26.47$ versus $90.83+12.36(\mathrm{p}=0.029)$, emotional domain $77.83+19.90$ versus $89.00+10.54(\mathrm{p}=0.015)$, social $79.67+25.05$ versus $94.83+9.87(\mathrm{p}=0.005)$, school domain $63.33+25.47$ versus $88.73+16.11(\mathrm{p}=<0.001)$ and psycho-social $72.96+20.81$ versus $91.17+9.54(\mathrm{p}=<0.001)$. This is shown in table 4. 


\section{Editorial}

Table 5 shows the quality of life of children with seizure disorder. Twenty-one (70\%) children each had good quality of life (total and psycho-social) on both parent- proxy reported scale and Self-reported scale, while 22(73.3\%) and 8(26.7\%) had good quality of life (physical domain) on parent-proxy reported scale.

Table-5: Quality of life of children with seizure disorder on both child self-reported and parent-proxy reported scales.

\begin{tabular}{|c|c|c|c|}
\hline & & $\begin{array}{c}\text { Child Self report } \\
\text { N (\%) }\end{array}$ & $\begin{array}{c}\text { Parent-proxy report } \\
\text { N (\%) }\end{array}$ \\
\hline Total & Good quality & $21(70)$ & $21(70)$ \\
\hline & Poor quality & $9(30)$ & $9(30)$ \\
\hline Physical & Good quality & $21(70)$ & $22(73.3)$ \\
\hline & Poor quality & $9(30)$ & $8(26.7)$ \\
\hline Psycho-social & Good quality & $21(70)$ & $21(70)$ \\
\hline & Poor quality & $9(30)$ & $9(30)$ \\
\hline
\end{tabular}

Table 6 shows the relationship between seizure variables and self reported quality of life (total). Nineteen children with generalized seizures had good quality of life while 2 children with partial seizures had good quality of life but the relationship between seizure type and health related quality of life was not statistically significant ( $\mathrm{p}-0.345)$. When health related quality of life was compared with the seizure frequency it was observed that children with no seizure the month before the study had good quality of life compared to those with seizures and this was statistically significant $(\mathrm{p}=$ 0.021). Health related quality of life was not influenced by the number of seizure medications the child is taking.

Table-6: Relationship between seizure variables and child self-reported health quality of life (total score).

\begin{tabular}{|c|c|c|c|c|}
\hline & Good quality & Poor quality & $\mathbf{X}^{\mathbf{2}}$ & p-value \\
\hline \multicolumn{5}{|c|}{ Seizure type } \\
\hline Generalized & 19 & 7 & 0.879 & 0.345 \\
\hline Partial & 2 & 2 & 11.587 & 0.021 \\
\hline \multicolumn{5}{|c|}{ Seizure frequency } \\
\hline No seizure & 16 & 4 & & \\
\hline Once a month & 0 & 3 & & \\
\hline Twice a month & 1 & 0 & & \\
\hline Thrice a month & 1 & 0 & & \\
\hline >thrice a month & 3 & \multicolumn{5}{|}{} \\
\hline \multicolumn{5}{|c|}{ Seizure medications } \\
\hline Monotherapy & 15 & 7 & 0.13 & 0.547 \\
\hline Two medications & 6 & 2 &
\end{tabular}

\section{Discussion}

This is the first study in Nigeria using the paediatrics quality of life inventory 4.0. Generic core scales (parent and child scales) to compare the health-related quality of life of children with epilepsy with that of apparently healthy controls.

The finding that majority of the children belonged to the upper and middle social classes could be due to the fact that these groups of people have the financial capability to shoulder the cost of investigations and treatment of seizure disorder. The female preponderance observed in this study is surprising as previous studies in this environment reported male preponderance in hospitalbased studies [21, 22, 23]. The reason had been that our society places more value on male children and so are given better healthcare for their survival and maintenance of family lineage. The observation that children with seizure disorder had significantly lower total mean scores than controls was also reported by other studies $[24,25,26]$. Miller et al reported that the health-related quality of life in children with seizure disorder compared with the controls is diminished in all functioning domains [24]. The mean scores on individual subscales of the health-related quality of life 


\section{Editorial}

were also significantly lower than those of apparently healthy controls. The sequence of scores from the lowest to the highest was as follows: school functioning, social functioning, physical and emotional functioning on the child self report scale; school functioning, emotional, physical and social functioning. School functioning was noted as the subscale that was most affected. In the school function domain, children with seizure disorder reported problems with paying attention in class, forgetting things, keeping up with school work, missing school because of not feeling well and missing school to go to the doctor or hospital.

School absence is a common problem among children with seizure disorder and this must have attributed to their poor school function [27]. Ibekwe et al reported that the mean school absence rate for children with seizure disorder was significantly higher than that of the controls $(p=0.001)$ [27]. In the social function domain, children with seizure disorder reported problems getting along with other children, other kids not making friends with them, other kids teasing them, not able to do things that other children their age can do, finding it hard to keep up when playing with other children.

Stigmatization is a major problem among children with seizure disorder in our environment due to belief that that seizure disorder is contagious and one can get infected by contact with saliva from the mouth of the child who is having a seizure episode $[12,28]$. In the emotional function domain, children with seizure disorder reported that they are easily angered, they feel sad, afraid and scared, they also have trouble sleeping and worry about what would happen to them. Seizure disorder in children can often be associated with anxiety, depression and low self-esteem. Emotional and psychiatric disorders have been reported among children with seizure disorder [2,3,4,29].

The findings that children whose seizures are wellcontrolled had better quality of life than those with poorly controlled seizures had been reported by other authors $[25,30]$.

\section{Conclusion}

Children with seizure disorder had lower health related quality of life than apparently healthy children. Children who had good seizure control had significantly higher quality of life than those with poor seizure control. Efforts should be geared towards achieving good seizure control among children with seizure disorder in our environment so as to improve the healthrelated quality of life of these children.

\section{Acknowledgement}

The Authors wish to thank the families and patients who took part in the study and the research team at Mapi Research Institute, Lyon, France who made the questionnaire for the study available at no cost.

Funding: Nil, Conflict of interest: None initiated, Perission from IRB: Yes

\section{References}

1. Senanayake N, Roman GC. Epidemiology of epilepsy in developing countries. Bull World Health Organ. 1993;71: 247-58.

2. Freilinger M, Reisel B, Reiter E, Zelenko M, Hauser E, Seidi R. Behavioral and emotional problems in children with epilepsy.J Child Neurol.2008; 21: 939-45.

3. Datta SS, Premkumar TS, Chandy S, Kumar S, Kirubakaran C, Gnanamuthu C, et al. Behaviour problemsin children and adolescents with seizure disorder: associations and risk factors. Seizure. 2005; 14: 190-7.

4. Lagunju IA, Omigbodun OO. Mental health problems in Nigerian children with epilepsy. Epilepsy and Behavior 2012; 2: 214-8.

5. Austin JK, Harezlak J, Dunn DW, Huster GA, Rose DF, Ambrosius WT. Behavior problems in children before first recognised seizures. Pediatrics 2001; 107: 115-22.

6. Caplan R, Siddarth P, Gurbani S, Ott D, Sankar R, Shields WD. Psychopathology and pediatric complex partial seizures: seizure-related, cognitive and linguistic variables. Epilepsia. 2004; 45: 1273-1281.

7. Dunn DW, Austin JK, Huster GA. Behaviour problems in children with new-onset epilepsy. Seizure. 1997;6: 283-7.

8. Dunn DW, Austin JK, Huster GA. Symptoms of depression in adolescents with epilepsy. J Am Acad Child Adolesc Psychiatry. 1999; 38: 1132-8.

9. Ettinger AB, Weisbrit DM, Nolan EE et al. Symptoms of depression and anxiety in pediatric epilepsy patients. Epilepsia. 1998; 39: 595-9.

10. Hoare P. The development of psychiatric disorder among school children with epilepsy. Dev Med Child Neurol. 1984; 26: 3-13. 


\section{Editorial}

11. Ott D, Caplan R, Guthrie D, et al. Measures of psychopathology in children with complex partial seizures and primary generalised epilepsy with absence. J Am Acad Child Adolesc Psychiatry. 2001; 40:907-14.

12. Asindi AA, Eyong K. Stigma on Nigerian children living with epilepsy. J Pediatr Neurol.2012;10(2):105-9.

13. Aronu AE, Ojinnaka NC. Psychiatric morbidity among parents of children with epilepsy in Enugu, Nigeria. Neurol Asia. 2009; 14: 15-20.

14. AronuAE, Iloeje SO. Behavioural problems of siblings of epileptic children in Enugu. Niger $\mathrm{J}$ Clin Pract 2011;14: 132-6.

15. World Health Organization, World Health Organization constitution. Basic documents, Geneva 1948.

16. Lagunju IA, Akinyinka $\mathrm{O}$, Orimadegun $\mathrm{A}$, Akinbami FO, Brown BJ, Olorundare E, et al. Healthrelated quality of life of Nigerian children with epilepsy. Afr J Neurol Science (AJNS). 2009; 28(1):

17. Oyedeji G. Socio-economic and cultural background of hospitalized children in Ilesha. Nig Medical Pract. 1985; 12: 111-7.

18. Varmi JW et al. The PedsQL: Measurement Model for the Pediatric Quality of Life Inventory. Medical Care. 1999; 37(2): 126-39.

19. Varmi JW, et al. The PedsQL ${ }^{\mathrm{TM}} 4.0$ : Reliability and validity of the Pediatric Quality of Life Inventory ${ }^{\mathrm{TM}}$ Version 4.0 Generic Core Scales in healthy and patient populations. Medical Care. 2001; 39(8): 800-12.

20. Huang I, Thompson LA, Chi YY, Knapp CA, Revicki DA, et al. The linkage between pediatric quality of life and health conditions. Establishing clinically meaningful cut-off scores for PedsQL. Value Health. 2009; 12(5): 773-81.
21. Akpan MU, Nyong EE, Abasiubong F. Pre-hospital treatment and outcome of status epilepticus in children in Nigeria.Case Study and CaseReport.2011;1(2):82-91.

22. Ekpe EE, Akpan MU. Poorly treated bronchopneumonia with progression to empyema thoracis in Nigerian children. TAF Prev Med Bull. 2010; 9(3): 181-6.

23. Ekpe EE, Akpan MU. Outcome of tube thoracostomy in paediatric non-traumatic pleural fluid collections. Afr J Paediatr Surg.2013; 10(2): 122-6.

24. Miller V, Palermo TM, Grewe S. Quality of life in pediatric epilepsy: demographic comparison with healthy controls. Epilepsy Behav. 2003; 4(1): 36-42.

25. Monir ZM, EL-Alameey IR, Eltahlawy.E. Health related quality of life of children with epilepsy in Egypt. J Arab Soc Med Res. 2013; 8: 53-66.

26. Liu X, Han Q. Risk factors on health-related quality of life in children with epilepsy. Clin Pediatr. 2015;54 (4): 1334-8.

27. Ibekwe RC, Ojinnaka NC, Iloeje SO. Factors influencing the academic performance of school children with epilepsy. J Trop Pediatr. 2007; 53(5): 338-43.

28. Ojinnaka NC. Teachers' perception of epilepsy in Nigeria: A community-based study. Seizure. 2002; 11: 386-91.

29. Ogun OC, Gbiri CA, Akinola OA, Akinola OE, Ajirotutu OF, et al. Psychosocial correlates of depression in children and adolescents with epilepsy in a Nigeria neuro-psychiatric hospital. J Clin Case Rep. 2012; 2: 152. Doi: 10.4172/2165-7920.1000152.

30. Nadkarni J, Jain A, Dwivedi R. Quality of life in children with epilepsy. Ann Acad Neurol. 2011; 14(4): 279-82.

\section{How to cite this article?}

Mkpouto Udeme Akpan, Frances Sam Okpokowuruk. Health-related quality of life of children with seizure disorder in Uyo, Nigeria. Int J Pediatr Res. 2018;5(5):251-257.doi:10.17511/ijpr.2018.105.02. 